\title{
Trust, Distrust, and Epistemic Injustice
}

Katherine Hawley August 2016 - word count 5976

\section{Introduction}

There are many overlapping concepts of trust within philosophy. These are multiplied still further when we look to other disciplines - such as psychology, economics, and sociology and when we reflect upon our ordinary ways of thinking and talking about trust. Sometimes trust is thought of as an emotionally-thrilling leap into the dark; sometimes it is pictured as a bloodless pragmatic choice, based on cost-benefit analysis. Paradigmatic settings for trust vary from our most intimate personal relationships to our interactions with government, media, or corporate brands. And we talk of trusting what someone says, trusting someone to do something, or simply trusting someone, all to varying degrees.

Absence of trust, likewise, is multi-faceted. It inherits all the conceptual variety associated with trust. Moreover, for any given notion of trust, there are at least three different ways in which trust can be absent. First, we may lack trust in a given situation because we think that neither trust nor distrust is merited, that trustworthiness is not at stake. For example, my neighbour is not a philosopher, and has not offered to write this chapter for me. So I do not trust my neighbour to write this chapter for me, but nor do I distrust her in that respect: I recognise that neither of these attitudes fits the situation. Second, we may lack trust through lack of evidence: we think that a situation is one in which either trust or distrust is appropriate, but we can't tell which of these is the right attitude. For example, suppose my neighbour has offered to care for my garden whilst I'm away, but I don't know whether she is trustworthy in such matters. I think that either trust is appropriate here, or else distrust is appropriate, but I don't know which.

Third, we may lack trust when we think that trust-or-distrust is appropriate, i.e. that trustworthiness is at stake, and moreover that trust is inappropriate. For example, suppose my neighbour has promised to turn off her music at midnight, but I know from bitter experience that she never keeps such promises. In such a situation my lack of trust amounts to distrust. Thus distrust should be distinguished from mere lack of trust, and from mere agnosticism about trust. The relationship between trust and distrust is in some ways analogous to that between justice and injustice: it is fruitful to examine justice through the lens of injustice, and likewise it is fruitful to examine trust through the lens of distrust (I pursue this project in Hawley (2014a)).

On any understanding of trust and distrust, these attitudes are intertwined with issues of social power (Allen (2017)). Trusting, distrusting, being trusted, and being distrusted can all flow from the exercise of social power, and all can have consequences for social power. When you trust someone, you make yourself dependent upon her, giving her a certain power over you: a trusted person enjoys a great deal of discretion in her action. But, as Spiderman reminds us, with great power comes great responsibility: when you place your trust in someone, that can be a way of imposing responsibilities upon her. Placing your trust can give you the power to tug at the other person's conscience, and the power to represent the trusted person as untrustworthy if your expectations are unmet. For these sorts of reasons, trust is not always welcomed by the trusted person.

Distrusting, or withholding trust, is also an exercise of social power: you may deny other people important opportunities when you fail to trust them, both through the practical consequences of your distrust and through its symbolic power. But these exercises of social power stand in complicated relationships to privilege and security: whilst those with few resources may be forced to trust others, since they have no alternative, those who are more comfortably situated can afford to be more trusting, since they can more easily bounce back if they get things wrong. Dimensions of privilege, security, resources, and comfort here include 
emotional stability, health, strong relationships, and access to reliable information, not just access to money or material goods.

Where there is social power, there is the potential for injustice, and there are many ways of linking discussions of trust and distrust with discussions of injustice. In this chapter, I focus on issues of trust and distrust which seem especially relevant to epistemic injustice, and in particular on issues where thinking about trust and distrust may help us crystallise questions which we might have missed otherwise; the chapter should of course be read in the context of the many complementary chapters which make up this Handbook.

\section{Trust, Distrust, and Reliance}

What kind of attitude is trust? Following Annette Baier (1986), recent philosophical literature has focused on a rich, normatively-laden attitude of trust, an attitude which is properly adopted towards other people, but not towards inanimate objects. This is the attitude I have when I trust my friend to show up for our habitual coffee date, rather than the attitude I have when I trust the coffee itself to keep me awake. Such discussions of trust typically focus on trusting people to act as we expect, in practical situations. As such, we might wonder how they can raise issues of distinctively epistemic injustice. But trusting people to do things often involves trusting them to be competent or skilful, i.e. evaluating them on epistemic grounds, so there is potential for epistemic injustice here. (I return to the contrast between 'epistemic trust' and 'practical trust' in the section which follows.)

Philosophers disagree about how exactly to characterise the difference between these attitudes (McLeod 2015 surveys the options, whilst Holton (1994) influentially connects this debate to Strawson's (1974) account of 'reactive attitudes'). But some common themes are as follows. If my friend does not show up, I am likely to feel resentful, to feel she owes me an apology, and if the stakes are high I may even feel betrayed. If my coffee does not keep me awake, I may feel disappointed, frustrated, and sleepy, but it would be an anthropomorphising confusion to resent the coffee, or feel betrayed by it. (I might reasonably feel that way towards the barista, however, if I was mistakenly served decaf.) If my friend is a regular no-show, we regard this as a moral flaw, a kind of selfishness or failure to meet obligations, whereas if the coffee regularly sends me to sleep we look for a different brand, rather than moralising about its vices. Moreover there may be a distinctive phenomenology or emotional colour involved when I trust my friend, one which is absent when I rely upon the coffee (Jones (1996) emphasises emotion, whilst Medina (2013: 79-80) makes the connection to injustice).

Analogously, we can distinguish between a normatively-laden attitude of distrust and a more mundane attitude of low expectations. I distrust certain politicians, but I merely have low expectations regarding the reliability of my clapped-out car. Distrust embodies a moral criticism, involving attitudes such as resentment, and may have a distinctive emotional colour. Mere low expectations lack those features, and seem more like a pragmatic accommodation to an imperfect material world rather than a bruised response to moral inadequacy.

The richer attitudes of trust and distrust are appropriately adopted towards people, and not towards cups of coffee or clapped-out cars. But the thinner attitudes of reliance or low expectations can sometimes be appropriately adopted towards people, as well as towards inanimate objects. I might rely on the noisy teenagers in the café to keep me awake, but I don't think they are obliged to do this, and I can't reasonably resent them if they do not. Similarly, I might have low expectations about my neighbour's dress sense, but it would be a mistake for me to distrust her in this respect: dressing badly is not a moral failing, and my neighbour doesn't owe me anything on this front. 
When we regard other people in these ways, there is a sense in which we treat them impersonally, as sources of noise or of sartorial displeasure. But often this is the appropriate, indeed the respectful thing to do: I would be absurdly presumptuous if I treated my neighbour's sense of style as a personalised issue between us, regarding her as untrustworthy when she wears that dowdy jacket, demanding apologies, or feeling resentful. However we can wrong other people when we go too far in the opposite direction, treating them impersonally in situations when we should recognise them as deserving something richer. If my friend promises to meet me for coffee, I should take her seriously as making a personal commitment to me. I may trust her or indeed distrust her, depending on her habits of punctuality. But if instead I simply make a practical estimation of whether she is likely to turn up, and do not engage my reactive attitudes, this is a way of failing to treat my friend as a mature adult. (This is why it is painfully diminishing to be told 'I'm not angry, I'm just disappointed'.) If this is my general approach to our interactions, then we are not really friends.

When thinking about the ways in which trust and distrust can allow for injustice, it is often useful to think about a two-part structure, and, correspondingly, two opportunities for justice or injustice. In situations where trust or distrust may be appropriate attitudes, we need to get two different things right. We need to grasp whether the situation is one where trustor-distrust is appropriate: 'no' for my neighbour's dress sense, 'yes' for my friend's promise to meet for coffee. And then if trust-or-distrust is appropriate, we need to grasp which of these is correct: should I trust my friend to show up, or should I distrust her? Getting things wrong at either stage has the potential to harm others. At the first stage, I might mistakenly fail to take my friend's promise seriously as a promise, or I might mistakenly think that my neighbour's outfits are a matter of trust-or-distrust for me. At the second stage, I might take my friend's promise seriously, but mistakenly distrust her, rather than giving her the trust she deserves. And at either stage our judgements may be guided by prejudice and biases.

\section{Epistemic Trust and Practical Trust}

We trust people's words, and we trust their actions; to put things somewhat differently, we trust people as speakers (or as writers, as signers, etc), and we trust people as actors. These contrasts are sometimes marked as distinctions between 'epistemic' and 'practical' trust. But the labels are unhelpful for several reasons, and the underlying distinction itself is often blurry. First, speaking is itself a way of acting, so when we trust people as informants this is an instance of trusting them as actors. Second, our trust in people's actions often involves trusting them to act as they said they would: I trust my friend to meet me for coffee as she promised.

Third, our trust in people's words can have both epistemic and practical consequences; likewise for our trust in people's actions. When someone offers me information, and I trust what she says, if all goes well I thereby gain testimonial knowledge; there may also be practical consequences, whether things go well or badly. When I trust someone to act in a certain way, then likewise if all goes well her behaviour can provide me with knowledge. For example, if a ship's captain trusts the lookout to warn her of icebergs, then the captain can know that there are no icebergs on the basis of the lookout's silence.

Fourth, even paradigmatic cases of trust in a speaker's words involve more than trust in her knowledgeability; trusting the speaker involves trust that she knows what she is talking about, trust that she is sincere, and potentially much more. As Miranda Fricker reminds us (2007: 45), accepting someone's testimony requires us to have faith in the speaker's competence but also in her sincerity; conversely, we can recognise incompetence and dishonesty as two different forms of untrustworthiness. I myself am inclined to regard competence, but not sincerity, as an epistemic matter: that's to say, I think that when we 
judge someone to be insincere, we do not thereby judge her as a knower. But Fricker regards both competence and sincerity as epistemic: this is because, inspired by Edward Craig (1990), she takes the capacity to convey one's knowledge to others as essential to very possession of knowledge. If one is regarded as chronically insincere, then one is not regarded as trustworthy. For Fricker, this means one is not in fact a knower.

Despite my complaints about the distinction between so-called 'epistemic' and 'practical' trust, it is clear that testifying - purporting to offer information to others - is an action with a special social significance both for speaker and for audience. Testifying is not the only way in which speech can have epistemic significance. Nevertheless, it is a type of speech - a type of action - which creates distinctive normative concerns, and distinctive opportunities for both justice and injustice. With that in mind, I will discuss injustice first in the context of trust and distrust in testimony, and then in the context of trust and distrust in action more generally.

\section{Testimony}

In ordinary language, the term 'testimony' is reserved for significant first-personal reports of witnessing, often in religious, legal, or journalistic contexts. But for philosophers, "testimony" encompasses the multitudinous ways in which we purport to provide information to one another, taking in idle gossip, scientific papers, encyclopaedia articles, and kindergarten teaching, amongst much else. When somebody testifies, seeming to tell me something, I may believe or fail to believe what I am told. Many contextual factors will combine to determine how much credibility I give to a speaker. And, as Fricker so powerfully articulates (2007), sometimes I give a speaker less credibility than she deserves, because of my prejudices about her social identity, perhaps as a woman, as a refugee, or as a octogenarian. Then I perpetrate a testimonial injustice upon her.

Other chapters in this Handbook discuss testimonial injustice (e.g. Battaly 2017; Wanderer 2017). What difference does it make if we think of this in terms of trust and distrust, rather than simply in terms of giving and withholding credibility? We could use 'trust' and 'distrust' as mere synonyms for giving and withholding credibility, in which case it would make no difference at all. But to make life more interesting, let's use those terms in a way which respects the distinction between rich, normatively-laden trust and distrust on the one hand, and mere reliance or low expectations on the other hand.

Which of these is the attitude we take to other people's testimony? Do we feel resentful or just disappointed when testimony turns out to be false? Do we understand the offering and accepting of testimony in richly normative terms? Perhaps it depends: testimony about important matters, or within a personal or professional relationship can feel more significant than testimony about trivia from strangers. Indeed, Wanderer (2017) argues that a pre-existing relationship can mean that epistemic injustice constitutes an epistemic betrayal. Nevertheless, even in the most low-stakes scenarios, we tend to moralise both intentional deception and reckless speculation disguised as sober fact (or 'bullshit' as it is technically known, following Frankfurt (2005)).

Some epistemologists argue that when a speaker offers her personal assurance to an audience, who then reward her with their trust, this improves the epistemic status of the beliefs formed by the audience (Moran 2005; Hinchmann 2005). On this picture, the intended audience acquires a distinctive epistemic justification which is unavailable to mere eavesdroppers, no matter how clearly they overhear the testimony. Other epistemologists deny the epistemic significance of trust (e.g. Lackey 2008). But even sceptics such as Lackey accept that testimony is typically intertwined with interpersonal normative expectations, opening up opportunities for resentment and gratitude, justice and injustice, whether or not these are epistemically significant. 
Following Craig (1990), Fricker distinguishes between treating someone as an informant, part of a community with common purposes, and treating that person as mere source of information (2007: 132). She argues that systematic testimonial injustice treats a speaker as a mere source of information, and is thereby a form of objectification. I would suggest instead that objectification arises when we disrespect people by offering them either mere reliance or low expectations, where trust or distrust would be more appropriate. Sometimes we are prepared only to feel pleased or disappointed, when it would be more respectful to feel grateful, angry or betrayed. Systematic testimonial injustice - systematic unfair distrust - is wrong, but not because it treats others as mere objects.

\section{Trustworthiness and untrustworthiness}

Epistemological discussions of testimony typically start by assuming that a speaker testifies that $p$, and is recognised as doing so, whether or not the audience believes what she says. Discussions of testimonial injustice often inherit that starting point. But there are also opportunities for injustice which arise before that point, as a potential audience decides who to ask, and where to direct their attention, as a potential speaker decides whether and how to speak, and as an audience interprets both the meaning of a speaker's words, and the force with which she utters them.

For example, Kristie Dotson (2011) identifies the phenomenon of 'testimonial smothering', in which a potential speaker decides to remain silent, recognising the potential audience's unwillingness or inability to appreciate what she might have said: perhaps the speaker fears the consequences of miscommunication, or perhaps she simply thinks the struggle is not worth her effort on this occasion. Similarly, Rebecca Kukla (2014) shows how social structures can unfairly determine whether a speaker manages to testify, or merely to suggest, speculate, or joke when she uses her words; Kukla calls this 'discursive injustice' (see also Anderson (2017)). And Andrew Peet (2015) shows how prejudicial stereotypes can help determine the meaning we attribute to other people's words, generating what Peet calls 'interpretative injustice'.

This rich array of work - of which these three papers are just a sample - illustrates the complexity of our social interactions around the offering, receiving, and evaluation of testimony (Hookway (2010) explores this complexity further). Whilst no single theoretical tool can neatly handle all this, we can make some progress by thinking in terms of trustworthiness and untrustworthiness, not just trust and distrust. When we think about trust and distrust in the context of testimony, we easily slip into an undue focus on situations in which a speaker is recognised as testifying that $p$, for some definite $p$, and an audience responds with either trust or distrust.

But we also judge one another's trustworthiness in more general terms, not just in respect of particular instances of testimony. When we judge someone to be trustworthy, we do not assume that they are omniscient, able to provide us with whatever information we need. But we do assume that a trustworthy person is able to judge her own competence, so that she will testify only in areas where she is indeed competent. Perhaps also we assume that a trustworthy person will speak up whenever her testimony is potentially relevant; this assumption is undermined by Dotson's account of testimonial smothering. Kukla's work shows how someone who is not taken seriously as testifying - someone who is heard as merely speculating - does not have opportunities to demonstrate her trustworthiness, since she is not viewed as a proper target of either trust or distrust. And Peet shows how, through audience misinterpretation, speakers can falsely appear to misjudge their own competencies in untrustworthy ways.

In my view, these phenomena around trustworthiness present us with a disturbing theoretical dilemma. On the one hand, we can think of trustworthiness (and of 
untrustworthiness) as an intrinsic feature of an individual, or at least as a disposition of the individual to respond in trustworthy fashion to various external challenges. We can then try to understand the ways in which such trustworthiness can be misunderstood, misperceived, or intentionally ignored by others. On this approach, injustices arise from the way in which an individual is unfairly and inaccurately represented by others as being untrustworthy.

These kinds of judgements of untrustworthiness can become a self-fulfilling prophecy. The various processes through which an individual comes to be regarded as untrustworthy may in turn damage her self-confidence, limit her access to sources of information, and/or render her less able to articulate her thoughts and opinions (Saul 2017; Carel and Kidd (2017).) This is a causal mechanism via which unfair treatment can reduce someone's trustworthiness, even when we recognise that being trustworthy is not the same as being regarded as trustworthy.

Alternatively, we can think of an individual's trustworthiness (or untrustworthiness) as not merely caused but constituted by the ways in she interacts with others, including the ways in which others perceive and represent her words and actions. Crudely speaking, we can identify trustworthiness with being regarded as trustworthy. We can then try to understand the ways in which people are rendered untrustworthy - or less trustworthy - by other people's interactions with them, or by other people's failures to offer opportunities of interaction. On this approach, injustices arise from the way in which an individual is unfairly made untrustworthy by others' interactions with her - not just through the causal consequences of others' interactions, but in virtue of the fact that trustworthiness is constituted by the regard of others.

Testimonial smothering again provides a useful illustration. As Dotson writes, '[i]n testimonial smothering, a speaker smothers her/his own testimony [i.e. decides not to speak] when an audience demonstrates testimonial incompetence for unsafe, risky testimony owing to pernicious ignorance' (2011: 250). When a speaker is smothered, does she merely disguise her own trustworthiness, or does she thereby actually become less trustworthy in virtue of her 'failure' to testify? This is an uncomfortable dilemma, since we seem forced to choose between a picture of the heroic individual unjustly misunderstood by others, and a picture of injustice so pervasive that it even undermines individual character traits, constitutively as well as causally. It is not yet clear which of these theoretical approaches will be most fruitful for the practical struggle against injustice; nor is it clear which of these is more respectful of the experiences of those who suffer most from injustice.

\section{Trust in Action}

Gerald Marsh (2011) identifies testimonial injustice as a special case of a more general phenomenon of injustice in trusting, arguing that understanding the significance of trust more generally is key to understanding the nature of testimonial injustices. He points out that, just as we assess informants in terms of their competence (knowledge) and sincerity, we also assess agents in terms of their competence to act, and their sincerity or good intentions in acting. Marsh explores the centrality of trust to social life, arguing that we owe one another a baseline level of trust, simply as fellow human beings, and that we harm one another when we do not offer this baseline trust.

Not every aspect of other people's behaviour is the proper target of our trust or distrust. My neighbour's habits of dress may reflect her taste, intentions and competencies, but I misunderstand our relationship if I make this an issue of trust or distrust between us, or regard this as evidence of my neighbour's trustworthiness or untrustworthiness. Much of our engagement in the social world is bound up with questions about when our behaviour is a matter for ourselves alone, and when it becomes an issue of trust or distrust for others; these 
boundaries can shift over time, and between different communities, making it difficult for an outsider to assimilate.

There is empirical controversy about whether multi-ethnic neighbourhoods typically have lower levels of social trust, and about what mechanisms might promote or reduce trust in such contexts (Schmid et al (2014) is an interesting recent contribution): lack of shared conventional expectations may make it more difficult to establish trustworthiness, or even to establish what trustworthiness requires of us. Again, we face the uncomfortable theoretical dilemma I outlined above: does moving to an unfamiliar setting render us untrustworthy in virtue of other people's attitudes towards us, or does it instead make it more difficult for people to recognise our underlying and authentic trustworthiness?

Assuming that we can fairly identify those situations in which others' behaviour is a test of their trustworthiness, how might epistemic injustice arise here? We often understand other people's behaviour as grounded in their practical competencies, skill or knowledgehow; where we think behaviour is not competence-based, we often regard this as problematic. This suggests that there are opportunities for epistemic injustice arising from systematic unfairness in the ways in which we attribute knowledge-how to the people around us, just as there can be systematic unfairness in our attributions of knowledge in testimonial contexts.

Unfairly underestimating other people's practical knowledge on the basis of their behaviour can take at least two forms. Prejudice may lead us to misjudge the quality of an action or performance: Goldin and Rouse (2000) showed that, when American orchestras began to audition players from behind an opaque screen, the proportion of women admitted rose significantly. Moreover prejudice may lead us to attribute evidently-high-quality action to luck rather than to skill or knowledge: Biernat and Kobrynowicz (1997) showed that, in simulated job applications, women and black people found it more difficult to prove that their successes were due to their own abilities.

Unfair distrust in practical contexts may arise from these sorts of prejudices in attributing success or knowledge-how. However distrust is often focused not upon competence but upon the other person's intentions, sincerity or goodwill. We may judge someone to be highly skilled, yet deeply untrustworthy: 'Machiavellian' characters deserve this verdict, as do classic evil geniuses. Where such judgements are unfair, due to systematic identity prejudices of the type discussed by Fricker (2007), is the resulting injustice a distinctively epistemic injustice, which harms the person in her capacity as a knower? I believe it is not, and I attempt to justify this claim in Hawley (2011). But setting this disagreement aside, considering trust and distrust in practical, not just testimonial contexts, can more generally give us fresh insights into the possibilities for epistemic justice and injustice.

\section{Uniqueness, Rationality, and Choice}

What is the difference between trusting someone in some respect and believing her to be trustworthy in that respect? One important difference between trust and belief is that, in certain circumstances, we can freely choose whether to trust, whereas we cannot simply choose whether to believe. Richard Holton (1994) has influentially argued that although evidence may sometimes require us to trust, or to distrust, we are often in a middle ground where each of trust and distrust seem permissible, and both options are available to us, though we cannot simultaneously choose both.

This is a complex issue, but in short there seems to be a smaller gap between genuinely trusting and "merely" acting as if you trust, than there is between genuinely believing and "merely" acting as if you believe: someone who systematically behaves as if she trusts is not merely pretending to trust, she is in fact trusting. In this context, philosophers sometimes write of 'therapeutic' trust, i.e. trust which is extended to someone 
who does not appear positively trustworthy, in the hope that such trust will in its turn encourage trustworthiness (Horsburgh 1960).

There are two complementary ways of thinking about this middle ground where trust seems to be a matter of choice; depending on which we endorse, there seem to be different consequences for issues of injustice. First, we can understand this as a psychological point about our thought processes: in such circumstances we do not inevitably find ourselves either trusting or distrusting, but instead these are attitudes we can actively and consciously adopt. In contrast, we do not typically experience belief formation in this active, conscious way.

Second, we can understand this as a normative point about rationality or justification for trust: in certain circumstances trust is justified, and distrust is justified (though holding both attitudes simultaneously is not justified), as is withholding from either trust or distrust. This contrasts with standard epistemological ways of thinking about belief, according to which in any given evidential situation, only one attitude can be rationally justified, even if it is difficult for us to tell which attitude that is (this principle is sometimes known as 'uniqueness'; White (2005)). The psychological claim and the normative claim are distinct: we may experience ourselves as choosing between options, even though one of these is rationally mandated, and conversely we may feel compelled to take one option even though others are rationally permissible.

Consider the psychological claim, that we can exercise control over our trusting and distrusting, and suppose this to be accurate in at least some cases. This would seem to have consequences for the ways in which we blame ourselves and others for injustices in trust and distrust: it seems easier and more fruitful to attribute blame for actions which seem to be under the actor's direct control. Moreover, the psychological claim of control may have consequences for which strategies we should adopt to remedy such injustices, both in ourselves and in others: changing our conscious actions is a different task from changing what seem to be unconscious habits (Saul (2017)).

Now consider the normative claim, that in certain circumstances there is no unique rationally-mandated degree of trust, but rather a permissible range of more-or-less trusting attitudes. If this is accurate, we face an intriguing challenge to the way in which epistemic injustice is standardly characterised. For Fricker, the central case of testimonial injustice is identity-prejudicial credibility deficit (2007: 28). Credibility deficit is defined both in counterfactual terms - by reference to the credibility the speaker would have received in the absence of prejudice (2007: 17) - and in terms of the audience's obligations. Fricker writes 'there is no puzzle about the fair distribution of credibility ... the hearer's obligation is obvious: she must match the level of credibility she attributes to her interlocutor to the evidence that he is offering the truth' (2007: 19).

This notion of credibility deficit seems to presuppose a unique 'right' level of credibility in any given situation; this is problematic if in certain situations trust is rationally permissible, but so is distrust (Hawley 2014b). One response would be to limit epistemic injustice only to those cases where prejudice takes us beyond what is rationally permissible, cases in which we distrust although trust is mandated. But this concedes too much: someone who always decides borderline cases in favour of men, and against women, may be systematically unjust even if any individual such decision is within the bounds of reasonableness, since trust is not mandated in any individual case.

Some people are cautious about trusting, whilst others are quicker to trust: these differences may be due to varying past experiences (including experiences of injustice), to varying significance of the stakes, or just to differences in personality. Some of us are willing to rely on our gut instincts about when to trust, whilst others of us are not: again, these differences may be explained in various different ways, including our past history of interaction with others, justly or unjustly. Trust typically involves risk, and we are familiar 
with the idea that people vary in their levels of risk aversion, so this should come as no surprise. Indeed, within certain limits, we can regard quite a large range of different attitudes to trust as both morally and rationally acceptable. But it does not seem acceptable to vary even within that 'acceptable' range based on considerations of race, gender, or class. Even if it is epistemically permissible to be somewhat mean-minded, and epistemically permissible to be fairly charitable, it is not morally permissible to switch between these doxastic policies on grounds of social identity. If and when we engage in such switching, we perpetrate epistemic injustice without breaking any epistemic rules.

\section{Acknowledgement}

This chapter was written during leave supported by a Leverhulme Major Research Fellowship, which I gratefully acknowledge.

\section{References}

Allen, Amy (2017) 'Power/Knowledge/Resistance: Foucault and Epistemic Injustice,' in Ian James Kidd, Gaile Pohlhaus, and José Medina (eds.) The Routledge Handbook to Epistemic Injustice. New York: Routledge.

Anderson, Luvell (2017) 'Epistemic Injustice and the Philosophy of Race,' in Ian James Kidd, Gaile Pohlhaus, and José Medina (eds.) The Routledge Handbook to Epistemic Injustice. New York: Routledge.

Baier, Annette C. (1986) 'Trust and Antitrust,' Ethics 96: 231-60.

Battaly, Heather (2017) 'Testimonial Injustice, Epistemic Vice, and Vice Epistemology,' in Ian James Kidd, Gaile Pohlhaus, and José Medina (eds.) The Routledge Handbook to Epistemic Injustice. New York: Routledge.

Biernat, Monica and Kobrynowicz, Diane (1997) 'Gender- and Race-Based Standards of Competence,' Journal of Personality and Social Psychology 72: 544-57.

Carel, Havi and Kidd, Ian James (2017) 'Epistemic Injustice in Medicine and Healthcare,' in Ian James Kidd, Gaile Pohlhaus, and José Medina (eds.) The Routledge Handbook to Epistemic Injustice. New York: Routledge.

Craig, Edward (1990) Knowledge and the State of Nature, Oxford: Clarendon Press.

Dotson, Kristie (2011) 'Tracking Epistemic Violence, Tracking Practices of Silencing,' Hypatia 26.2: 236-57.

Frankfurt, Harry (2005) On Bullshit, Princeton NJ: Princeton University Press.

Goldin, Claudia and Rouse, Cecilia (2000) 'Orchestrating Impartiality: the Impact of 'Blind' Auditions on Female Musicians,' American Economic Review 90: 715-41.

Fricker, Miranda (2007) Epistemic Injustice, Oxford: Oxford University Press.

Hawley, Katherine (2011) 'Knowing How and Epistemic Injustice', in John Bengson and

Marc A. Moffett (eds.), Knowing How, Oxford: Oxford University Press, 283-99.

Hawley, Katherine (2014a) 'Trust, Distrust and Commitment', Nôus 48: 1-20.

Hawley, Katherine (2014b) 'Partiality and Prejudice in Trusting', Synthese 191: 2029-45.

Hinchmann, Edward S. (2005) 'Telling as Inviting to Trust,' Philosophy and

Phenomenological Research 70.3: 562-87.

Holton, Richard (1994) 'Deciding to Trust, Coming to Believe,' Australasian Journal of Philosophy 72: 63-76.

Horsburgh, H.J.N. (1960) 'The Ethics of Trust', Philosophical Quarterly 10: 343-54.

Jones, Karen (1996) 'Trust as an Affective Attitude', Ethics 107: 4-25.

Kukla, Rebecca (2014) 'Performative Force, Convention and Discursive Injustice,' Hypatia 29.2: 440-57.

Lackey, Jennifer (2008) Learning From Words, Oxford: Oxford University Press. 
Marsh, Gerald (2011) 'Trust, Testimony and Prejudice in the Credibility Economy', Hypatia, 26.2: 280-93.

Medina, José (2013) The Epistemology of Resistance: Gender and Racial Oppression, Epistemic Injustice, and Resistant Imaginations, Oxford: Oxford University Press.

Moran, Richard (2005) 'Getting Told and Being Believed', Philosophers' Imprint 5.5: 1-29.

Peet, Andrew (2015) 'Epistemic Injustice in Utterance Interpretation', Synthese, forthcoming DOI 10.1007/s11229-015-0942-7.

Saul, Jennifer (2017) 'Implicit Bias, Stereotype Threat, and Epistemic Injustice', in Ian James Kidd, Gaile Pohlhaus, and José Medina (eds.), The Routledge Handbook to Epistemic Injustice. New York: Routledge.

Strawson, P.F. (1974) 'Freedom and Resentment', in his Freedom and Resentment, London: Methuen, 1-25.

Schmid, Katharina, Al Ramiah, Ananthi and Hewstone, Miles (2014) 'Neighborhood Ethnic Diversity and Trust: the Role of Intergroup Contact and Perceived Threat', Psychological Science 25.3: 665-74.

Wanderer, Jeremy (2017) 'Varieties of Testimonial Injustice', in Ian James Kidd, Gaile Pohlhaus, and José Medina (eds.), The Routledge Handbook to Epistemic Injustice. New York: Routledge.

White, Roger (2005) 'Epistemic Permissiveness', Philosophical Perspectives 19: 445-59.

\section{Further Reading}

C. McLeod provides an excellent overview of philosophical work on trust in her "Trust" in The Stanford Encyclopaedia of Philosophy (Fall 2015 Edition), Edward N. Zalta (ed.), URL = http://plato.stanford.edu/archives/fall2015/entries/trust/>. K. Hawley's Trust: a Very Short Introduction (Oxford University Press: 2012) draws on several academic disciplines, aimed at a general reader. J. Medina The Epistemology of Resistance (New York: Oxford University Press) explores many relevant issues in depth. K. Jones "The Politics of Credibility," in L.M. Antony and C.E. Witt (eds.) A Mind of One's Own (Boulder CO: Westview Press 2002) is a rich investigation of epistemic injustices written by a leading philosopher of trust. R. Putnam's Bowling Alone: The Collapse and Revival of American Community (New York: Simon and Schuster, 2000) is a classic sociological study of trust, social capital, and inequalities. 